\title{
Towards a consensus on mode II adhesive fracture testing: experimental study.
}

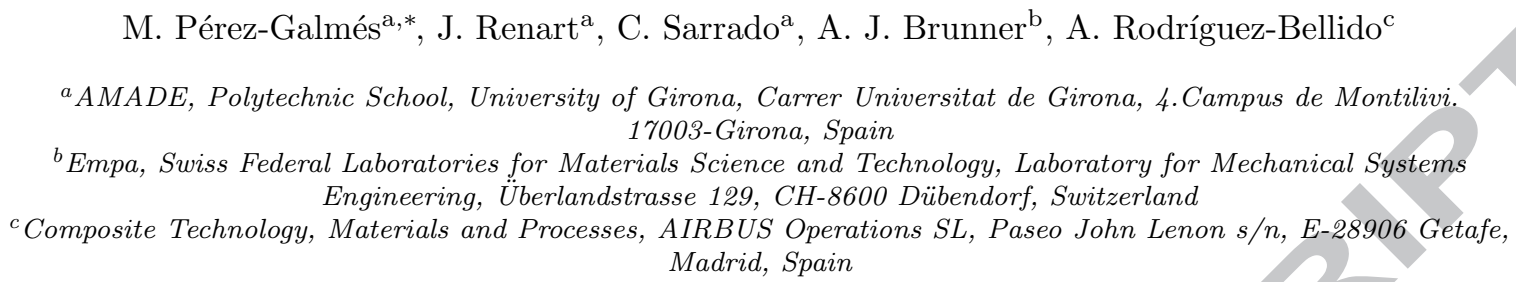

\section{Abstract}

The objective of this work is to define reliable test methodologies and data reduction methods to obtain comparable results among the most common mode II test methodologies: the End-Notched Flexure (ENF), the End-Load Split (ELS), the 4-point End-Notched Flexure (4ENF), and the Mixed Mode Bending (MMB) test at $100 \%$ of mode II.

For this reason, an experimental test campaign consisting of the abovementioned four mode II test methods was carried out. The $J$-integral was implemented in the ELS, the ENF and the MMB tests and a $J$-integral closed form was developed and implemented for the 4 ENF test. Then the $J$-integral was compared to the data reduction methods based on Linear Elastic Fracture Mechanics (LEFM). The results obtained from the $J$-integral based methods were independent from the test methodology and obtained very good agreement among the tests.

In addition, from the experimental results the advantages and drawbacks of the different test procedures are analysed and discussed, concluding that the ELS test is the most suitable to measure mode II fracture toughness of adhesives.

Keywords: Mode II fracture toughness, Bonded joints, $J$-integral, FRP, Mechanical testing

\section{Introduction}

Nowadays, adhesive bonding is widely used in industrial applications as an alternative to traditional mechanical fasteners, especially in lightweight structures. Moreover, the use of adhesives is of great

\footnotetext{
${ }^{*}$ Corresponding author. Tel.: +34 972418817

Email addresses: magdalena.perez@udg.edu (M. Pérez-Galmés), jordi.renart@udg.edu (J. Renart) Preprint submitted to Theoretical and Applied Fracture Mechanics 
importance in composite materials repair.

Bonded joints are designed such that the adhesive is loaded in the direction of its maximum strength (i.e. shear), whereas tension or peel stresses are minimized. For this reason, determining mode II fracture toughness is extremely important.

There are various standardized test methodologies available to determine the mode II fracture toughness of fibre-reinforced polymer composites, namely the End-Notched Flexure (ENF) test [1], the End-Loaded Split (ELS) test [2] and, alternatively, the Mixed Mode Bending (MMB) test [3] used at $100 \%$ mode II ratio. Although not standardized, the Four End-Notched Flexure (4ENF) test, due to its intrinsic stable configuration, also provides a suitable approach which has been used by many authors [4-9]. All these methods are widely used by the scientific community and the industry to obtain the fracture properties of the materials.

Assuming mode II fracture toughness as a material property, many authors have compared different tests and have obtained different results $[5,9-12]$. These studies realized that one of the main problems in mode II testing is the poor comparability among the existing test methods. The causes of such discrepancies in results are diverse, ranging from the friction and large deflections involved, to the complex damage mechanisms occurring at the crack tip [5, 13-17].

In the case of adhesive bonded joints, they have been reported to entail a large Fracture Process Zone (FPZ) at the crack front due to the plasticity of the adhesive layer $[18,19]$. Therefore, analysing situations involving large FPZ may fall outside the scope of the mode II delamination standards data reduction methods because they are based on Linear Elastic Fracture Mechanics (LEFM).

The interest in bonded joints failure has led to new data reduction methods being developed to determine fracture toughness in a non-linear framework. One that has enjoyed particular success is the $J$-integral developed by Rice [20], a path-independent contour integral that can be interpreted as a non-linear energy release rate. Simple closed form solutions of the $J$-integral have been used to obtain fracture toughness in tests such as ENF [21], ELS [22] and MMB [23], which could be good alternatives to the current data reduction methodologies. 
75 Polyester carrier. resin used.

The main problem in mode II adhesive testing is the poor reproducibility of the results among the different test types, from which many data reduction methodologies have emerged. The objective of this work is to obtain a reliable mode II fracture toughness test for structural adhesives.

To achieve this, a mode II experimental test campaign of bonded joints between Carbon Fibre Reinforced Polymers (CFRP) was carried out. Two different specimen configurations were used, which are manufactured with the same adhesive but with a different adherend.

Four mode II test methodologies were compared: ENF, ELS, 4ENF and MMB at $100 \%$ ratio of mode II. Different data reduction methods based on both LEFM and the $J$-integral were applied to each test methodology. A $J$-integral closed form solution for the $4 \mathrm{ENF}$ test is presented, as it is the only one from the tests studied for which a $J$-integral closed form does not exist in the literature. In view of the results, a discussion on the suitability of the tests and data reduction methods for the analysis of adhesives is presented.

\section{Experimental test campaign}

The tests were performed in the ISO17025 and NADCAP (National Aerospace and Defense Contractors Accreditation Program) for non-metallic materials certified AMADE research group testing laboratory, at the University of Girona. The specimens tested were $25 \mathrm{~mm}$ wide, $210 \mathrm{~mm}$ long, $4.8 \mathrm{~mm}$ thick with an adhesive layer of $0.22 \mathrm{~mm}$. To induce a $60 \mathrm{~mm}$ long artificial crack in the bonding line, one doubled layer of PTFE (Polytetrafluoroethylene) film of about $0.02 \mathrm{~mm}$ to 0.03 $\mathrm{mm}$ was placed in between the two substrates.

Two different specimen types (M1 and M2) were manufactured with the same adhesive but each with a different adherend. The adhesive was a secondary bonded epoxy resin embedding a Mat /

Each two adherend used consist of carbon tape epoxy prepreg multidirectional balanced lay-ups $\left(\left[0^{\circ} / 0^{\circ} /+45^{\circ} /-45^{\circ} /+45^{\circ} /-45^{\circ}\right]_{s}\right)$, precured in an autoclave. They differ in the type of fibres and 
Surface activation of the adherends for bonding was done by abrasion followed by solvent cleaning, and after, bonded specimens were cured in autoclave.

The adherends and the adhesive are typical materials employed in the aeronautical industry mainly used on primary and secondary aircraft structures. For reasons of confidenciality, the names of the constituents and their basic properties are not listed.

From each material, M1 and M2, five different panels were made. In order to obtain comparable specimens, from each panel, four specimens were obtained and each one was tested with a different test type (ELS, ENF, 4ENF and MMB respectively). By doing so, each batch consist of five specimens, each one coming from a different panel made with the same material as described before. With the aim of avoiding unstable crack initiation from the insert, before the mode II tests a pre-crack in mode I was made in all the specimens following the ISO25217 [24] standard. The pre-crack propagation length differed from the standard's specifications, depending on the desired mode II initial crack length, but minimum propagation of $5 \mathrm{~mm}$ was ensured.

After the pre-crack tests, the final crack length was measured with an optical microscope and marked on the edge of the specimen. Afterwards, the edge was marked every millimetre with a vertical line from the initial crack tip, $a_{0}$, to the final propagation length, $a_{f}$ (c.f. Figures 1, 2, 4 and 5). The mode I pre-cracks and the mode II tests were carried out under displacement control in a universal test machine. During the mode II tests, the load, the displacement, the crack length, and the rotations at the loading application points and at the supports were recorded. The load and the displacement were obtained from the test machine. During the test, the crack length was optically monitored along one edge of the specimens using a video acquisition system consisting of a Canon $550 \mathrm{D}$ camera with a macro lens, mounted on a travelling fixture and the crack length considered from the visual observation of the end the crack, but not the deformed vertical lines. The rotations were measured with capacitive inclinometers NA3-30 from SEIKA Mikrosystemtechnik GmbH, with a resolution of 0.005 degrees and a maximum linearity deviation over the whole measurement range ( \pm 30 degrees $)$ of 0.06 degrees, according to the manufacturer's specifications. 
Different methods were used for the data reduction: LEFM-based and $J$-integralbased methods.

The LEFM-based methods are derived from the Irwin-Kies formula,

$$
\mathcal{G}_{I I c}=\frac{P^{2}}{2 W} \frac{\partial C}{\partial a}
$$

where $P$ is the load, $W$ is the specimen width, $C$ is the compliance (the ratio between the displacement and the load, $\delta / P)$ and $a$ is the crack length.

To obtain the compliance, with respect to crack length rate $(\partial C / \partial a)$, for each test geometry the literature presents several LEFM-based data reduction methodologies which are based on Beam Theory (BT), Compliance Calibration (CC) and the area method.

In BT-based methods, a closed form solution of the compliance $(C)$ is derived based on specimen geometry using Beam Theory. In CC-based methods, a compliance calibration is performed before the test by loading and unloading the specimen at different initial crack lengths, and a relationship between $C$ and $a$ is obtained. This function is then derived and applied in equation 1. Finally, in the area method, the area enclosed in the load-displacement diagram (i.e. total energy dissipated) with respect to the total amount of cracked area formation (i.e. $\Delta a W$ ) is measured, and considered to be the fracture toughness value.

Within the non-linear elastic fracture mechanics framework, and in the particular case of a two-dimensional elastic problem, the $J$-integral is defined as

$$
J=\int_{\Gamma}\left[\omega \mathrm{d} x_{2}-T_{k} \frac{\partial u_{k}}{\partial x_{1}} \mathrm{~d} s\right](k=1,2)
$$

where $w$ is the strain energy density, $T_{k}$ is the tractions vector, $u_{k}$ are the displacements vector and $\mathrm{d} s$ is the length increment along a contour path $\Gamma$ surrounding the crack. Several $J$-integral closed form solutions have been derived for different test geometries [21-23]. In these, all the dissipation mechanisms are considered inside the FPZ.

The parameters required for the data reduction are summarized in Table 1, and the different test 
geometries, instrumentation and data reduction methods are described in the following subsections.

\begin{tabular}{|c|c|c|c|c|c|c|}
\hline & \multirow{2}{*}{ Parameter } & \multirow{2}{*}{ Sensor } & \multirow{2}{*}{$J$-integral ${ }^{1}$} & \multicolumn{3}{|c|}{ LEFM-based } \\
\hline & & & & $\mathrm{BT}$ & $\mathrm{CC}$ & Area \\
\hline \multirow{5}{*}{ Before testing } & Thickness $(H)$ & Caliper & - & $\checkmark$ & - & - \\
\hline & Width $(W)$ & Caliper & $\checkmark$ & $\sqrt{ }$ & $\checkmark$ & $\checkmark$ \\
\hline & Initial crack length $\left(a_{0}\right)$ & Optical microscope & - & 1 & & $\checkmark$ \\
\hline & Set up geometrical parameters $(L, c, \ldots)$ & Caliper & $\checkmark$ & $\checkmark$ & $\checkmark$ & - \\
\hline & Fitting parameters $\left(\Delta_{\text {clamp }}, m, \ldots\right)$ & Compliance Calibration test & - & - & $\checkmark$ & - \\
\hline \multirow{4}{*}{ During the test } & Load $(P)$ & Load cell & $\checkmark$ & $\checkmark$ & $\checkmark$ & $\checkmark$ \\
\hline & Displacement $(\delta)$ & Crosshead displacement & - & $\checkmark$ & $\checkmark$ & $\checkmark$ \\
\hline & Crack length $(a)$ & Camera & - & $\checkmark$ & - & - \\
\hline & Rotations $(\theta)$ & Inclinometers & $\checkmark$ & - & - & - \\
\hline
\end{tabular}

${ }^{1}$ In the $4 \mathrm{ENF}$ test the specimen thickness is required to take into account friction effects only.

Table 1: Measurements before testing and during the test.

\subsection{End-Loaded Split (ELS) test}

The ELS tests were performed in a test rig designed in accordance with the ISO15114 standard [2].

The sliding fixture leads the horizontal displacement of the specimen, while the load is applied vertically through a block bonded at the bottom face of the cracked part of the specimen. The ELS test configuration is shown in Figure 1.

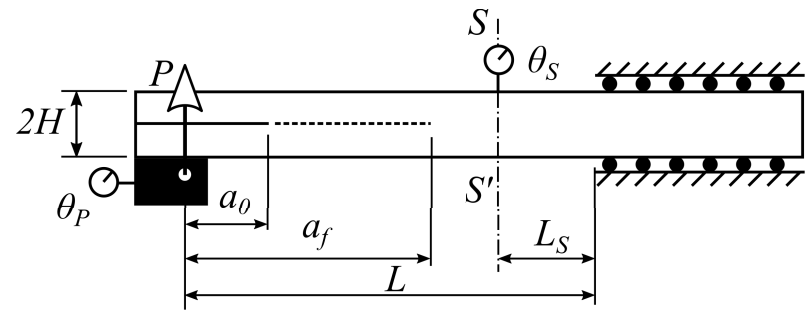

Figure 1: ELS geometry and instrumentation. Supports and loading applicators are represented in black. Two inclinometers are bonded at the load application points and at section $S$ - $S^{\prime}$. Dimensions: $L=100 \mathrm{~mm}$, $a_{0}=55, a_{f}=95 \mathrm{~mm}$ and $L_{S}=10 \mathrm{~mm}$.

The specimens were instrumented with two inclinometers, one bonded at the top face of the specimen at section $S$ - $S^{\prime}$ and the other at the load application block (c.f. Figure 1). 
The span length $(L)$ was set to $100 \mathrm{~mm}$ with an initial crack length $\left(a_{0}\right)$ of $55 \mathrm{~mm}$. The tests were run at a $2 \mathrm{~mm} / \mathrm{min}$ loading speed until the crack exceeded the final crack length mark $\left(a_{f}=95 \mathrm{~mm}\right)$ and then they were unloaded at $10 \mathrm{~mm} / \mathrm{min}$ speed.

Before the test, a clamp calibration was performed in accordance with ISO 15114 [2]. These preliminary calibration tests were used to obtain the ELS clamp correction and the specimen flexural modulus $(E)$; data required in Simple Beam Theory (SBT) and Corrected Beam Theory using Effective crack length (CBTE) data reduction methods. In the $J$-integral data reduction method, these previous calibrations can be avoided and the flexural modulus is obtained directly from the test by measuring the rotated angles at the loading application point and at section $S$ - $S^{\prime}$ (c.f. Figure 1). Different data reduction methods were used to obtain the fracture toughness (Table 2). The first three methods were the Simple Beam Theory (SBT), the Experimental Compliance Method (ECM) and the Corrected Beam Theory using Effective crack length (CBTE).

The fourth method used corresponds to the area method (AREA) proposed by Hashemi et al. [7] where the global energy dissipated (area enclosed in the load-displacement diagram per unit of delaminated area $(\Delta a W))$ is evaluated.

Finally, the fracture toughness was measured by the $J$-integral, following the procedure proposed in a previous work [22] in which the $J$-integral was obtained from the applied loads, the rotations at the loading point and at section $S-S^{\prime}$, and the strain profile at section $S-S^{\prime}$. The strain profile was determined using the Beam Theory approach.

A detailed description of the data reduction methods can be found in each of the references included in Table 2.

\subsection{End-Notched Flexure (ENF) test}

While ENF tests were performed in a test rig designed according to delamination standard ASTM D7905 [1], the span length was enlarged to obtain a larger propagation region for the total FPZ development. The specimen, with a pre-crack, was sustained by two rollers and the load was applied centered on the top face of the specimen. Figure 2 shows a schematic representation of the ENF test 


\begin{tabular}{lll}
\hline \hline Method & Expression for fracture toughness & References \\
\hline $\mathrm{ECM}^{1}$ & $\mathcal{G}_{I I}=\frac{3 P^{2} a^{2} m F}{2 W} ; C=C_{0}+m a^{3}$ & {$[2]$} \\
$\mathrm{SBT}^{1,3}$ & $\mathcal{G}_{I I}=\frac{9 P^{2} a^{2} F}{4 W^{2} H^{3} E} ; C=\frac{\delta}{P}=\frac{33^{3}+L^{3}}{2 W H^{3} E}$ & {$[2]$} \\
$\mathrm{CBTE}^{1,2,3}$ & $\mathcal{G}_{I I}=\frac{9 P^{2} a_{e}^{2} F}{4 W^{2} H^{3} E} ; a_{e}=\left(\frac{1}{3}\left(2 W \frac{C}{N} H^{3} E-\left(L+\Delta_{\text {clamp }}\right)^{3}\right)\right)^{1 / 3}$ & {$[2]$} \\
$\mathrm{AREA}^{4}$ & $\mathcal{G}_{I I}=\frac{A 10^{6}}{\Delta a W}$ & {$[7]$} \\
$J_{\text {-integral BT }}^{5}$ & $J_{I I}=\frac{3}{5} \frac{P^{2}}{G_{12} W^{2} H}+\frac{P}{W}\left(\tan \theta_{P}-\tan \theta_{S}\right)-\frac{E H}{3}\left(\frac{3}{2} \frac{P\left(L-L_{S}\right)}{E W H^{2}}\right)^{2}$ & {$[22]$} \\
\hline
\end{tabular}

${ }^{1}$ Correction factor $F$ for large displacements, included as described in [2].

${ }^{2}$ Correction factor $N$ for load-block effects included as described in [2].

${ }^{3} E$ deduced from slope $(m)$ of the clamp calibration data, i.e. the slope of the linear regression to the $C^{1 / 3}$ versus $L$ data, $E=1 /\left(2 W(H m)^{3}\right)$.

${ }^{4} A$ is the integration of the area of the load-displacement curve.

${ }^{5}$ The flexural modulus is deducted from the rotations at the loading application point $\left(\theta_{P}\right)$ and at section $S-S^{\prime}\left(\theta_{S}\right) \cdot E=\frac{-3 P\left(3 a_{0}^{2}+\left(L-L_{s}\right)^{2}\right)}{4 W H^{3}\left(\theta_{P}-\theta_{S}\right)}$.

Table 2: ELS data reduction methods.

geometry and its instrumentation.

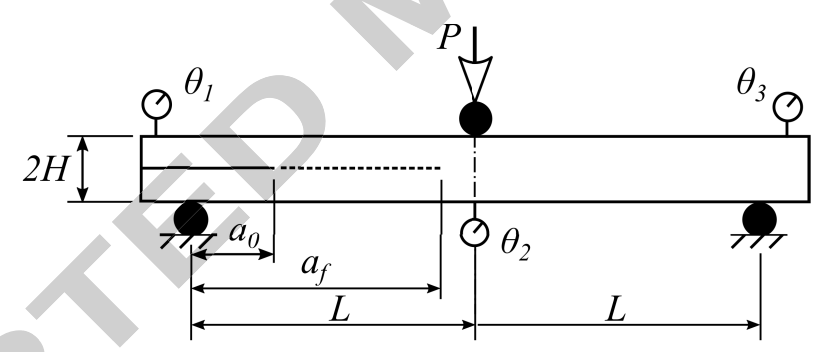

Figure 2: ENF specimen, test geometry and instrumentation. Black circles correspond to the bottom supports and the centered loading application roller, and white circles represent the inclinometers. Dimensions used were: $L=60 \mathrm{~mm}$ and $a_{0}=35 \mathrm{~mm}, a_{f}=60 \mathrm{~mm}$ and loading roller diameter $=10 \mathrm{~mm}$.

The loading process was executed at $1 \mathrm{~mm} / \mathrm{min}$ until the crack visually reached the final

delamination crack length $\left(a_{f}\right)$ or the system stiffened (when the FPZ reached the loading restrained section). Following this, the specimen was unloaded at $25 \mathrm{~mm} / \mathrm{min}$.

Different data reduction methods were used to measure fracture toughness. The methods based on LEFM were the Simple Beam Theory (BT) [13, 25], the Corrected Beam Theory (CBT) [13, 26, 27], and three compliance calibration based methods, called CCM, CC2 and CC3, according to the number of terms used in the third order polynomial used in the calibration, linear regression [27, 28], 
second order [29] and third order [4, 30], respectively.

The compliance calibration was done by loading and unloading the specimen at different crack lengths, without propagation. The crack lengths used for calibrations were $15 \mathrm{~mm}, 20 \mathrm{~mm}, 25 \mathrm{~mm}$, $30 \mathrm{~mm}$ and $40 \mathrm{~mm}$.

As in the ELS test, the area method (AREA) proposed by Hashemi et al. [7] was considered in the analysis.

Finally, the fracture toughness was measured using the $J$-integral by following the procedure

proposed by Stigh et al. [21]. For this purpose, three inclinometers were bonded to the specimen to measure the rotations at the contact points. The two external inclinometers $\left(\theta_{1}\right.$ and $\left.\theta_{3}\right)$ are located between the line of the reaction force and the end of the beam while the centered inclinometer $\left(\theta_{2}\right)$ is located aligned with the upper loading roller.

Table 3 summarizes the ENF data reduction methods used.

\begin{tabular}{|c|c|c|}
\hline Method & Expression for fracture toughness & References \\
\hline $\mathrm{BT}^{1}$ & $\mathcal{G}_{I I}=\frac{9 P^{2} a^{2}}{16 W^{2} H^{3} E}$ & {$[13,25]$} \\
\hline $\mathrm{CBT}^{2}$ & $\mathcal{G}_{I I}=\frac{9 P^{2} a^{2} C_{0}}{2 W\left(2 L^{3}+3 a_{0}^{3}\right)}$ & {$[13,26,27]$} \\
\hline $\mathrm{CCM}$ & $\mathcal{G}_{I I}=\frac{3 P^{2} m a}{2 W} ; C=C_{\alpha}+m a^{3}$ & {$[27,28]$} \\
\hline $\mathrm{CC} 2$ & $\mathcal{G}_{I I}=\frac{P^{2}}{2 W} \frac{\partial C}{\partial a} ; C=C_{\alpha}+C_{\beta} a+C_{\gamma} a^{3}$ & {$[29]$} \\
\hline CC3 & $\mathcal{G}_{I I}=\frac{P^{2}}{2 W} \frac{\partial C}{\partial a} ; C=C_{\alpha}+C_{\beta} a+C_{\gamma} a^{2}+C_{\lambda} a^{3}$ & {$[4,30]$} \\
\hline $\mathrm{AREA}^{3}$ & $\mathcal{G}_{I I}=\frac{A 10^{6}}{\Delta a W}$ & {$[7]$} \\
\hline$J$-integral & $J_{I I}=\frac{P}{2 W}\left(\tan \left(\theta_{1}\right)+\tan \left(\theta_{3}\right)-2 \tan \left(\theta_{2}\right)\right)$ & {$[21]$} \\
\hline \multicolumn{3}{|c|}{$\begin{array}{l}{ }^{1} E \text { from elastic range load-displacement curve; } E=\frac{2 L^{3}+3 a_{0}^{3}}{8 W H^{3}} \frac{\Delta P}{\Delta \delta} \text {. } \\
{ }^{2} C_{0} \text { is the compliance of the initial, linear portion of the load versus } \\
\text { displacement curve. } \\
{ }^{3} \mathrm{~A} \text { is the integration of the area of the load-crosshead displacement } \\
\text { diagram. }\end{array}$} \\
\hline
\end{tabular}

Table 3: ENF data reduction methods summary. 


\subsection{Four-point End Notched Flexure (4ENF) test}

The Four-point End Notched Flexure tests were run in a test fixture designed by the authors, see Figure 3 .

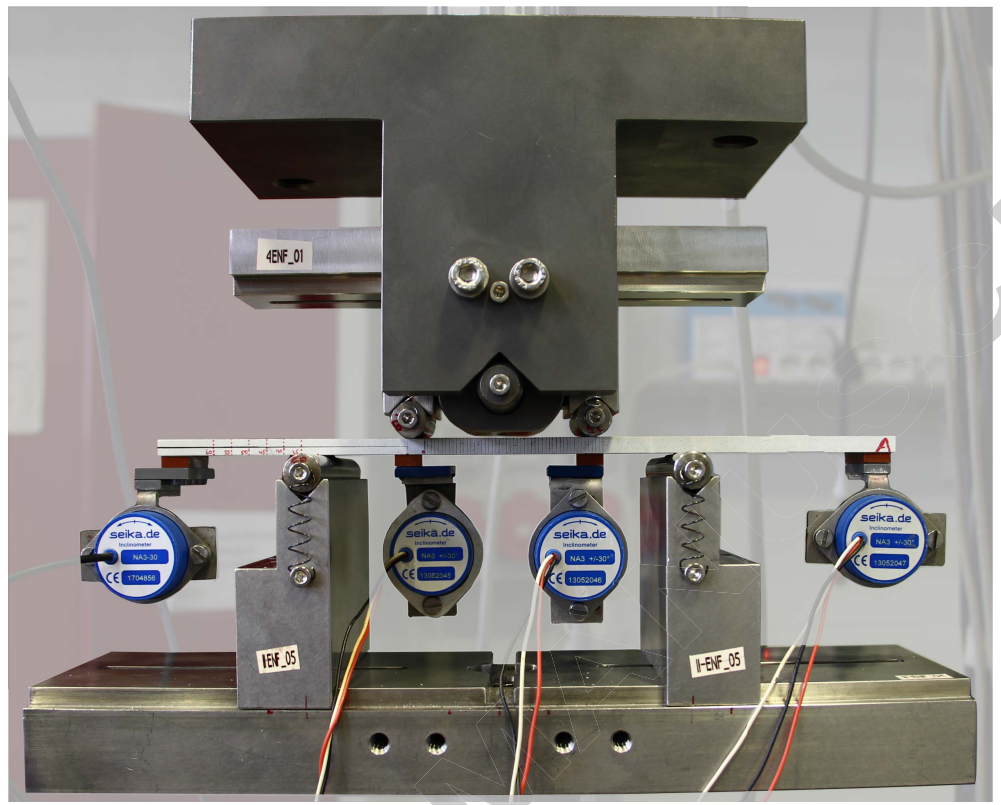

Figure 3: $4 \mathrm{ENF}$ test fixture.

The bottom part of the fixture is the same as in the ENF and the top part allows for the free rotation of the upper rollers, allowing them to be in permanent contact with the specimen.

A schematic of the $4 \mathrm{ENF}$ test geometry and the location of the inclinometers used to measure the rotations at the loading application edges is shown in Figure 4.

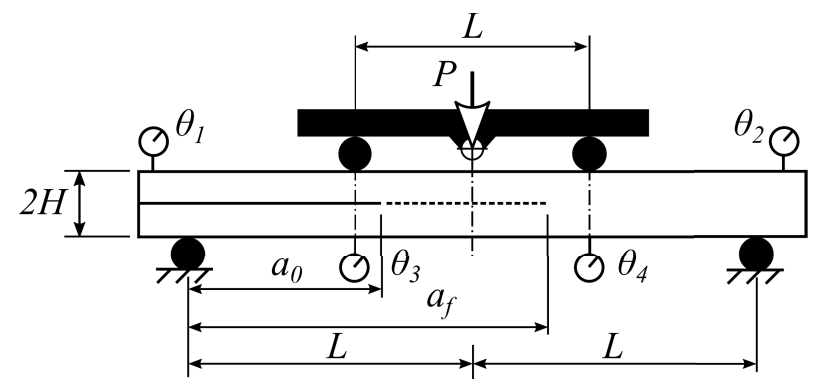

Figure 4: $4 \mathrm{ENF}$ geometry and instrumentation. Black circles correspond to supports and loading rollers and white circles represent the inclinometers. Dimensions used were: $L=60 \mathrm{~mm}, a_{0}=35 \mathrm{~mm}, a_{f}=60 \mathrm{~mm}$ and roller radius $=5 \mathrm{~mm}$.

The total lower span length $(2 L)$ was set to $100 \mathrm{~mm}$. The upper rollers were centered at a span 
distance of $L=60 \mathrm{~mm}$. The initial crack length was set to $35 \mathrm{~mm}$ from the left bottom roller. The specimen was loaded at a speed of $1 \mathrm{~mm} / \mathrm{min}$ speed and unloaded at $5 \mathrm{~mm} / \mathrm{min}$. Tests were stopped when the crack tip (visually inspected by the camera) reached the final distance of $60 \mathrm{~mm}\left(a_{f}\right)$. Three LEFM-based data reduction methods were considered: the Simple Beam Theory (SBT) [8], the Experimental Compliance Method (ECM) [5], and the Compliance Calibration Method (CCM) [5]. Additionally, a $J$-integral data reduction method, which takes into account the frictional effects was developed for this test:

$$
J_{I I}=\frac{P}{2 W}\left(-\sin \theta_{1}-\sin \theta_{2}+\sin \theta_{3}+\sin \theta_{4}-\frac{3 P L \mu \cos \theta_{3}}{2 W H^{2} E}\right)
$$

where $P$ is the applied load, $W$ is the specimen width, $H$ is the half thickness of the specimen, $L$ is the half span length, $E$ is the adherend longitudinal modulus, $\mu$ is the friction coefficient between cracked surfaces, $\theta_{1}$ and $\theta_{2}$ are the rotations of the specimen at the arms between the edge of the bottom rollers and the end of the specimen and $\theta_{3}$ and $\theta_{4}$ are the rotations of the specimen at the upper roller application edges (c.f. Figure 4). Details of the $J$-integral derivation for the 4ENF test are described in Appendix A.

The last term in equation (3) takes into account the frictional effects. Davidson et al. [5] estimated the frictional resistance to the crack propagation in specimens similar to M1 and M2, obtaining a friction coefficient of $\mu=0.345$ with a coefficient of variation of $8.5 \%$. This friction coefficient value was used in the analysis to account for the friction effects.

Table 4 summarizes the $4 \mathrm{ENF}$ data reduction methods used in the fracture toughness calculation.

\subsection{Mixed Mode Bending (MMB) test}

While the Mixed Mode Bending (MMB) tests were done according to the ASTM D6671 test standard [3], the span length was modified to ensure total FPZ development during testing. The test geometry and instrumentation is schematically shown in Figure 5. The specimens are subjected to loading by two load blocks (bonded at the pre-cracked end of the specimen) and supported by the 


\begin{tabular}{lll}
\hline \hline Method & Expression for fracture toughness & References \\
\hline $\mathrm{BT}^{1}$ & $\mathcal{G}_{I I}=\frac{9 P^{2} L}{32 W H^{2} E}$ & {$[8]$} \\
$\mathrm{ECM}^{2}$ & $\mathcal{G}_{I I}=\frac{P^{2} m}{2 W} ; m=\frac{C-C_{0}}{a_{V I S}}$ & {$[5]$} \\
$\mathrm{CCM}^{3}$ & $\mathcal{G}_{I I}=\frac{P^{2} C_{1}}{2 W} ; C_{1}=\frac{C-C_{0}}{a_{c a l}}$ & {$[5]$} \\
$\mathrm{AREA}^{4}$ & $\mathcal{G}_{I I}=\frac{A 10^{6}}{\Delta a W}$ & {$[7]$} \\
$J$-integral ${ }^{1,5} J_{I I}=\frac{P}{2 W}\left(-\sin \theta_{1}-\sin \theta_{2}+\sin \theta_{3}+\sin \theta_{4}-\frac{3 P L \mu \cos \theta_{3}}{2 W H^{2} E}\right)$ & eq. $(3)$ \\
\hline \hline${ }^{1} E=\frac{L^{2}\left(L+9 a_{0}\right)}{32 W} \frac{\Delta P}{\Delta \delta}$ & \\
${ }^{2} \mathrm{Direct}$ measure of $a_{V I S}$ during the test. & \\
${ }^{3} C_{1}$ obtained from compliance calibration $\left(C\right.$ Vs $\left.a_{\text {cal }}\right)$. & \\
${ }^{4} A$ is the area of the load-crosshead displacement curve. & \\
${ }^{5} \mu=0.345[5]$. &
\end{tabular}

Table 4: Summary of 4ENF data reduction methods.

lower base of the test tool. The load is introduced vertically via the upper lever which pushes the specimen down at its half span length point and, at the same time, pulls the upper arm of the cracked region up by its end. The length of the lever arm $(c)$ is used to adjust the mode mixture. To apply a pure mode II, it was set to $c=L / 3,[3]$. The loading process was done at $0.5 \mathrm{~mm} / \mathrm{min}$ until the crack visually reached the final delamination crack length $\left(a_{f}\right)$ or the system stiffened. The specimen was then unloaded at $2.5 \mathrm{~mm} / \mathrm{min}$.

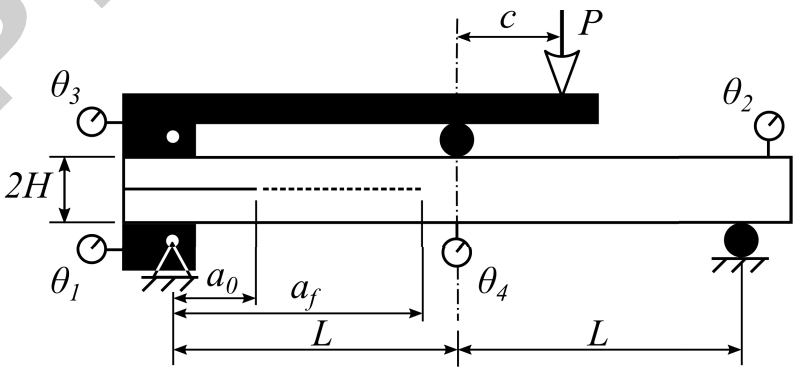

Figure 5: MMB geometry and instrumentation. In black, the supports and the loading applicators, white circles represent the inclinometers. Dimensions used were: $L=60 \mathrm{~mm}, a_{0}=35 \mathrm{~mm}, a_{f}=60 \mathrm{~mm}$ and roller radius $=5 \mathrm{~mm}$.

Two data reduction methods were used in calculations. Firstly, the method proposed in standard [3], which is based on crack length measurement $(a)$, 


$$
\mathcal{G}_{I I}=\frac{9 P^{2}(c+L)^{2} a^{2}}{16 W^{2} H^{3} L^{2} E_{1 f}}
$$

where $E_{1 f}$ is the modulus of elasticity in the fibre direction measured in flexure,

$$
E_{1 f}=\frac{8 a_{0}^{3}(3 c+L)^{2}+\left[6 a_{0}^{3}+4 L^{3}\right](3 c+L)^{2}}{16 L^{2} W H^{3}\left(\frac{1}{m}-C_{s y s}\right)}
$$

and $C_{s y s}$ is the compliance of the MMB test system, $m$ is the slope of the load-displacement curve and $a_{0}, c, L, W$ and $H$ are geometric parameters of the test (see Figure 5).

On the other hand, the $J$-integral was evaluated according to the expression [23],

$$
J_{I I}=\frac{P}{W}\left[\left(\frac{1}{2}-\frac{c}{2 L}\right) \tan \theta_{1}+\left(\frac{c}{2 L}+\frac{1}{2}\right) \tan \theta_{2}+\frac{c}{L} \tan \theta_{3}-\left(\frac{c}{L}+1\right) \tan \theta_{4}\right]
$$

where $P$ is the applied load, $W$ is the specimen width, $L$ is the half span length, $c$ is the lever arm and $\theta_{1}, \theta_{2}, \theta_{3}$ and $\theta_{4}$ are the rotations of the specimen at the supports and at the loading application points (see Figure 5)

\section{Results and discussion}

The load-displacement curves of all the specimens tested are shown in Figure 6. The curves are grouped by test configuration (ENF, ELS, MMB and 4ENF) and material (M1 and M2). No curves were obtained for M2 specimens of $4 \mathrm{ENF}$ and MMB test configurations, since a premature failure occurred in the adherend, invalidating the results.

Large differences in the load-displacement curves between the tests are observed, due to their intrinsic configuration. For example, the ELS test involves low loading values but large deflections, whereas in the $4 \mathrm{ENF}$ high loads are reached with small deflections.

In addition, the 4 ENF load-displacement curves differ from the others due to their intrinsic stable configuration. The load is kept constant during the steady state propagation [8]. 
On the other hand, as the crack was allowed to propagate all the way to the load point in the ELS, the ENF and the MMB tests, when the FPZ reached the clamp point (in the ELS test) or restrained sections (in the ENF and the MMB tests), a non-linear behaviour in load-displacement was observed. Finally, differences between initial stiffness in the load-displacement curves for the same batch were observed. The first cause is related to the precision on positioning the specimen or bonding the load block to obtain the desired initial crack length, $a_{0}$, which is a manual procedure. Secondly it is worth noticing that every batch is formed by specimens comming from differents panels. 


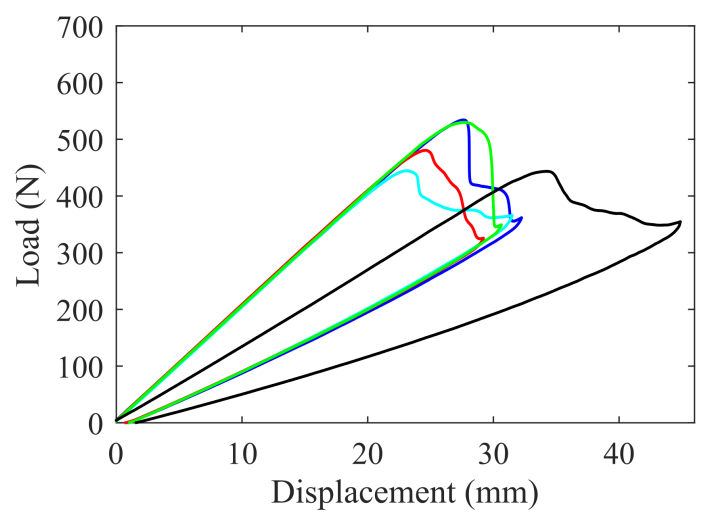

(a) ELS-M1

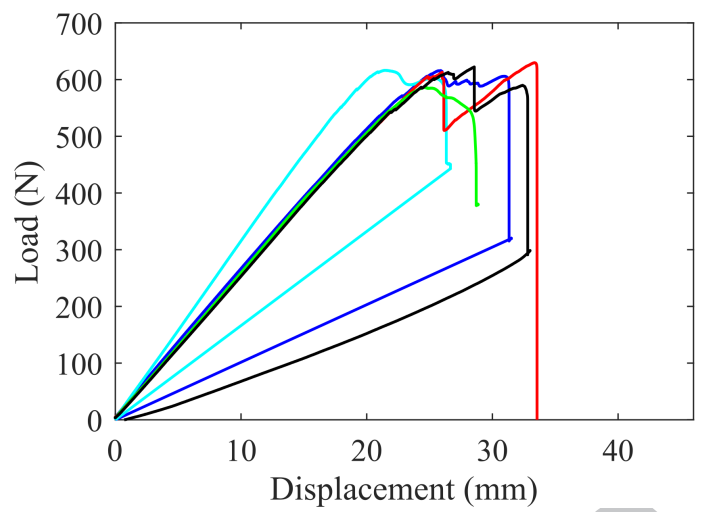

(c) ELS-M2

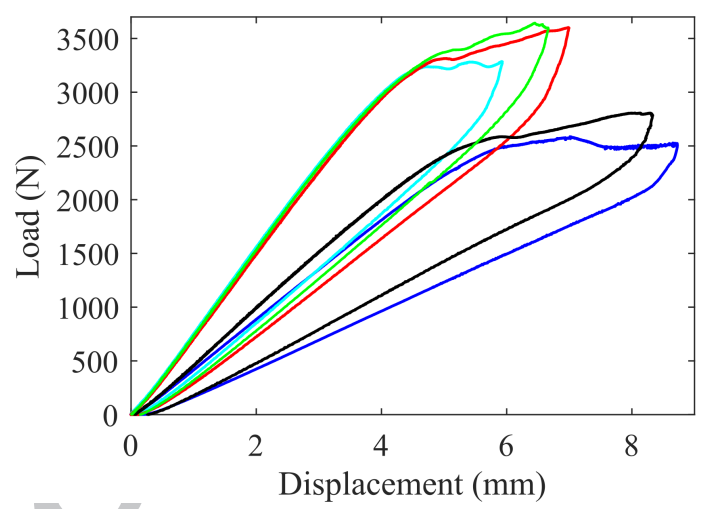

(e) 4ENF-M1

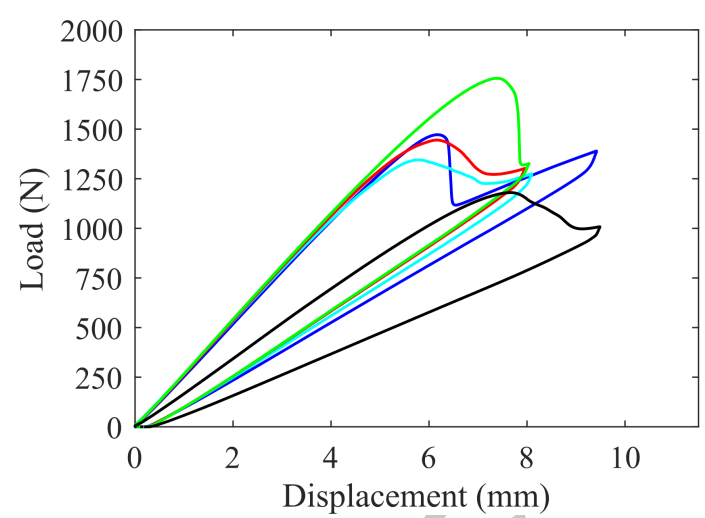

(b) ENF-M1

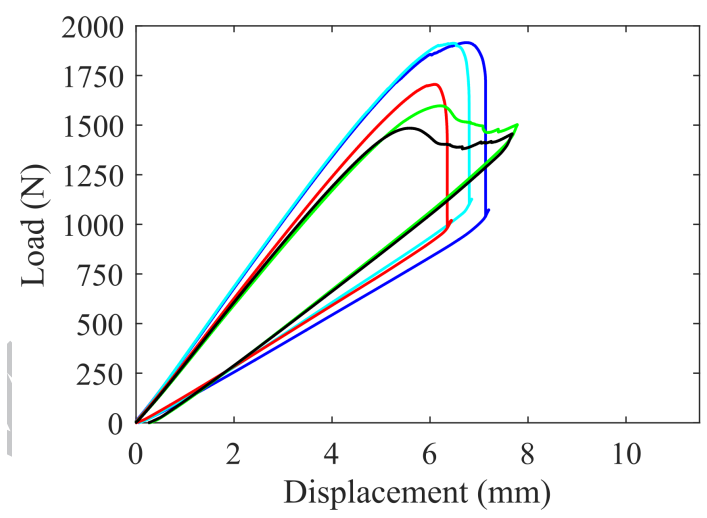

(d) ENF-M2

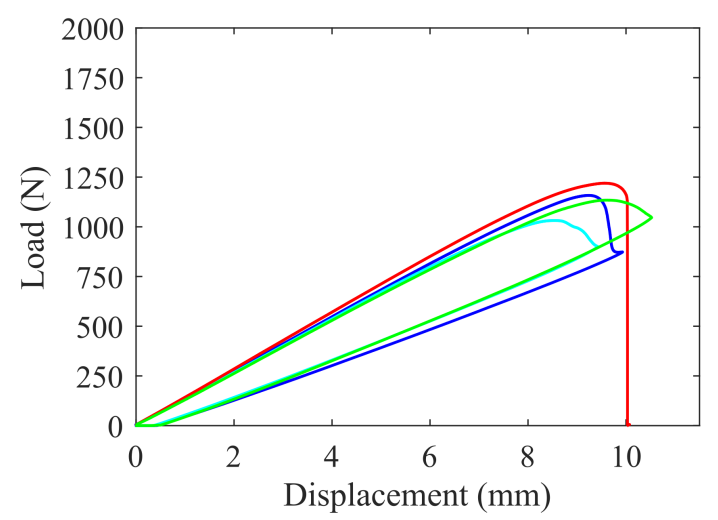

(f) MMB-M1

Figure 6: Load-displacement curves of tested specimens.

Figure 7 shows the $R$-curves (energy release rate vs. crack length), obtained from each data

reduction method, for a representative M1 specimen from each test. For convenience, the results are normalized with respect to the averaged value of $J_{I I c}$ obtained from M1 specimens tested with the 


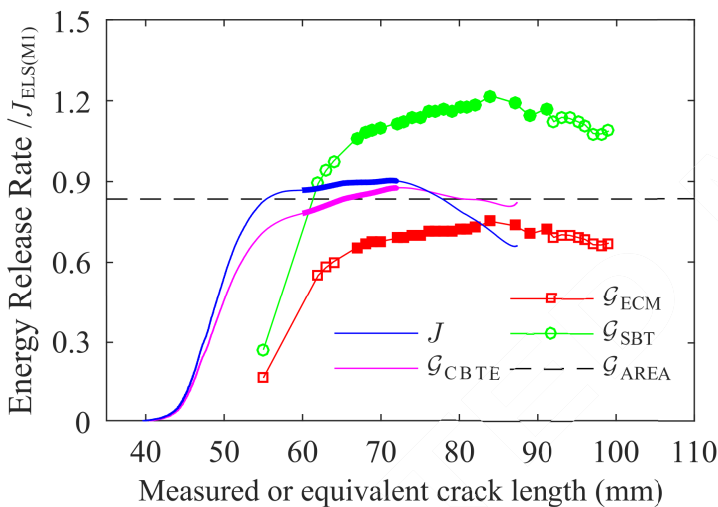

(a) ELS

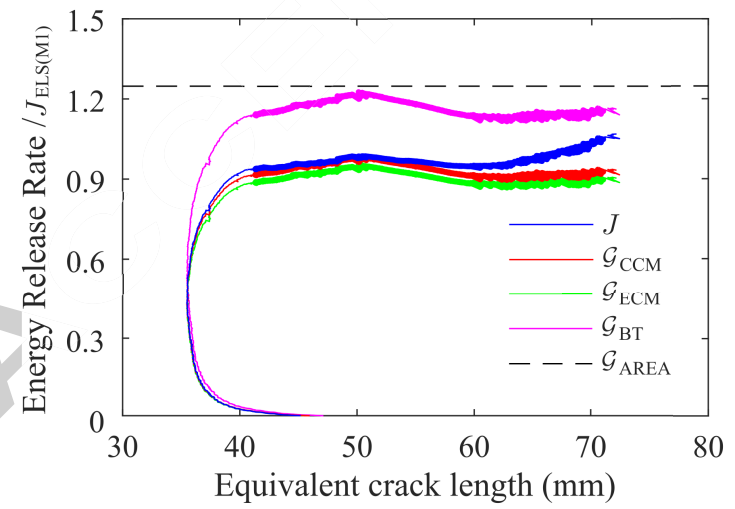

(c) $4 \mathrm{ENF}$

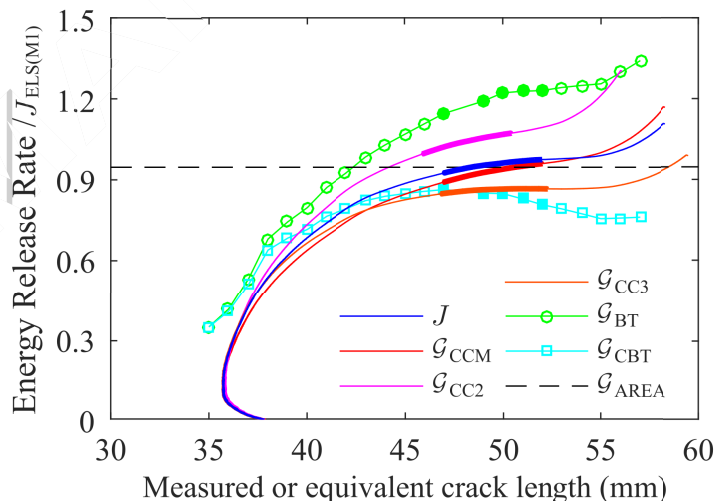

(b) ENF

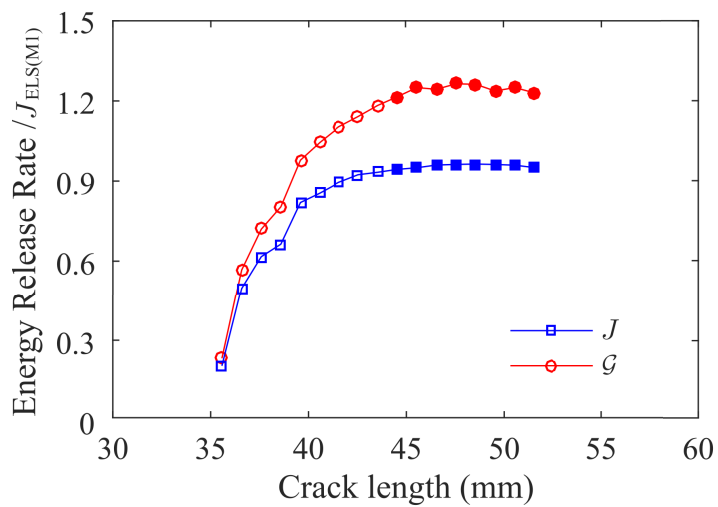

(d) $\mathrm{MMB}$

Figure 7: $R$-curve for each data reduction method of a representative M1 specimen from each batch. The energy release rate values are normalized with respect to the averaged value of $J_{I I c}$ from the M1 ELS batch (blue line in (a)). 
For each test and data reduction method, the fracture toughness is obtained from the plateau value.

Tables 5 to 8 list the average values of the fracture toughness and the standard deviation of each specimen batch. Each table provides information from one of the tests, i.e. Table 5 corresponds to the ELS, Table 6 to the ENF, Table 7 to the 4 ENF and Table 8 to the MMB. The columns indicate the data reduction method described in Section 2 and the rows the materials: M1 and M2. As previously stated, Tables 7 and 8 only show results from M1 because no results were obtained for material M2. All the values are normalized with respect to $J_{I I c}$ from the M1 obtained from the ELS test (Table 5). It is worth noticing that cohesive failure within the adhesive occurred in all specimens, except for the unstable propagation cases.

\begin{tabular}{lcccccc}
\hline \hline \multicolumn{2}{l}{ Batch } & $J_{I I c}$ & $\mathcal{G}_{I I c}(\mathrm{CBTE})$ & $\mathcal{G}_{\text {IIc }}(\mathrm{ECM})$ & $\mathcal{G}_{\text {IIc }}(\mathrm{SBT})$ & $\mathcal{G}_{\text {IIc }}(\mathrm{AREA})$ \\
\hline \multirow{2}{*}{$\mathrm{M} 1$} & Average & 1.00 & 0.94 & 0.68 & 1.22 & 0.92 \\
& $\mathrm{SD}^{1}$ & 0.17 & 0.11 & 0.11 & 0.20 & 0.15 \\
\hline \multirow{2}{*}{$\mathrm{M} 2^{2}$} & Average & 1.06 & 1.10 & 1.12 & 1.15 & - \\
& $\mathrm{SD}^{1}$ & 0.07 & 0.09 & 0.35 & 0.29 & - \\
\hline \hline
\end{tabular}

1 Standard Deviation.

${ }^{2}$ Final unstable crack growth invalidate $\mathcal{G}_{I I c}$ (AREA) data reduction method.

Table 5: ELS tests summary of results. All values are normalized with respect to the averaged value of $J_{I I c}$ from the M1 ELS batch.

Table 5 summarizes the ELS test results for materials M1 and M2. There are no values from the AREA method for the M2 batch because unstable propagation occurred after reaching steady state propagation, thus invalidating the measure of the final crack length. Some of the data reduction methods present large differences with respect to the reference value and between them (i.e. $\mathcal{G}_{I I c}$ $(\mathrm{ECM})$ and $\mathcal{G}_{I I c}(\mathrm{SBT})$, having differences of more than a $20 \%$ in the mean value). Furthermore, the average fracture toughness of each batch results in large SD for all test methods, probably due to the fact that each batch contains specimens from different panels. However, the discrepancies between the data reduction methods are too large to be considered as material heterogeneity. Therefore, to a large extent they must be attributed to the data reduction method used. From the comparison 
between M1 and M2, the authors expected no changes in the fracture toughness, because the adhesive layer was the same. In this sense, the $J$-integral and the CBTE are the data reduction methods that provide fewer differences between both materials, with $J$-integral giving the smallest difference. The relative error between both methodologies is less than $6 \%$. A discrepancy of $\mathcal{G}_{I I c}$ $(\mathrm{ECM})$ and $\mathcal{G}_{I I c}(\mathrm{SBT})$ results compared to those obtained with the CBTE method was expected, as this has been stated in a round-robin study on carbon-fibre epoxy material [31].

\begin{tabular}{ccccccccc}
\hline \hline \multicolumn{2}{l}{ Batch } & $J_{I I c}$ & $\mathcal{G}_{I I c}(\mathrm{CCM})$ & $\mathcal{G}_{I I c}(\mathrm{CC} 2)$ & $\mathcal{G}_{I I c}(\mathrm{CC} 3)$ & $\mathcal{G}_{I I c}(\mathrm{BT})$ & $\mathcal{G}_{I I c}(\mathrm{CBT})$ & $\mathcal{G}_{I I c}(\mathrm{AREA})$ \\
\hline \multirow{2}{*}{$\mathrm{M} 1$} & Average & 0.99 & 1.00 & 1.01 & 1.03 & 1.23 & 0.87 & 1.02 \\
& $\mathrm{SD}^{1}$ & 0.17 & 0.15 & 0.13 & 0.28 & 0.21 & 0.18 & 0.11 \\
\hline \multirow{2}{*}{$\mathrm{M} 2$} & Average & 0.98 & 1.01 & 1.07 & 1.26 & 1.41 & 1.04 & 0.98 \\
& $\mathrm{SD}^{1}$ & 0.22 & 0.18 & 0.30 & 0.54 & 0.31 & 0.16 & 0.28 \\
\hline \hline
\end{tabular}

${ }^{1}$ Standard deviation.

Table 6: ENF tests summary of results. All values normalized with respect to averaged value of $J_{I I c}$ from the M1 ELS batch.

Similarly to what it is observed in the ELS results, there are significant differences in some of the methods (of more than $20 \%$ ). Only the $J$-integral and CCM provide values of $\mathcal{G}_{I I c}$ closer to those obtained from the ELS test. Besides this, both methods are independent of the adherend used, having small differences, of less than $2 \%$, in the fracture toughness measurement between M1 and M2. The increment in the number of terms in the third order polynominal used in the calibrations (CC2 and CC3 in Table 3), which may be interpreted as an improvement in the correlation between $C$ and $a$, has in some cases, a negative effect on the fracture toughness measurement, increasing the difference between the $J_{I I c}$ from the M1 ELS and the $\mathcal{G}_{I I c}(\mathrm{CC} 3)$ from M2 ENF up to $26 \%$. As the calibrations have been run in a crack length range between $10 \mathrm{~mm}$ to $40 \mathrm{~mm}$ and the crack propagation region is from $35 \mathrm{~mm}$ to $60 \mathrm{~mm}$, the discrepancy may be attributed an inadequate definition of the calibration range.

It is also observed that the standard deviation of the $J$-integral obtained with the ENF is higher 
than the homonym obtained from the ELS. This increment may have been produced by the fact that in ENF tests the self-similar growth region is smaller than in the ELS (c.f. Figures 7b and 7a, respectively), consequently increasing the difficulty in defining a propagation range in the $R$-curve, thus incrementing the dispersion in the results.

Table 7 shows a summary of results obtained in the 4 ENF tests. In those carried out with M2 adherend, failure occurred at the initial stage of propagation and the results could not be obtained. None of the data reduction methods takes into account the friction effects, albeit except for the $J$-integral, in which the friction coefficient is defined as $\mu=0.345[5]$.

\begin{tabular}{lccccc}
\hline \hline M1 batch & $J_{I I c}$ & $\mathcal{G}_{I I c}(\mathrm{CCM})$ & $\mathcal{G}_{I I c}(\mathrm{ECM})$ & $\mathcal{G}_{I I c}(\mathrm{BT})$ & $\mathcal{G}_{I I c}(\mathrm{AREA})$ \\
\hline Average & 0.96 & 1.08 & 0.93 & 1.54 & 1.28 \\
$\mathrm{SD}^{1}$ & 0.18 & 0.15 & 0.10 & 0.24 & 0.44 \\
\hline \hline
\end{tabular}

${ }^{1}$ Standard deviation.

Table 7: $4 \mathrm{ENF}$ summary of results. All values normalized with respect to the averaged value of $J_{I I c}$ from the M1 ELS batch.

Again, the $J$-integral offers similar results to those obtained from the ENF and ELS tests. Results from the CCM are also in fairly good agreement with those obtained from the other tests. On the other hand, large differences are encountered in the methods that directly depend on the crack length measurement, i.e. BT and AREA. Despite also depending on the crack length measurements, like the CCM, the ECM provides acceptable results of $\mathcal{G}_{I I c}$ (less than $10 \%$ difference). The discrepancies between the $J$-integral and the other methods can be explained by the friction effects and the difficulties in mode II crack length measurement.

As in the $4 \mathrm{ENF}$ test, in the MMB tests M2 specimens were broken before crack propagation, thus invalidating the results. For the M1 specimens, the results obtained following the MMB test standard [3] $\left(\mathcal{G}_{I I c}\right)$ are higher than those obtained in the ENF, ELS or 4ENF tests, similar to what occurred in the previous test methodologies that depend on crack length measurements. Again the the $J$-integral offers close values to the previous tests. 


\begin{tabular}{lcc}
\hline \hline M1 batch & $J_{I I c}$ & $\mathcal{G}_{I I c}$ \\
\hline Average & 0.93 & 1.33 \\
$\mathrm{SD}^{1}$ & 0.11 & 0.24 \\
\hline \hline
\end{tabular}

${ }^{1}$ Standard deviation.

Table 8: MMB tests summary of results. All values normalized with respect to the averaged value of $J_{I I c}$ from the M1 ELS batch.

To graphically observe the deviation between the methods, Figure 8 shows the average results, with their corresponding standard deviation, for the $J$-integral and compliance calibration based methods (except the CC2 and CC3 from ENF). In essence, all the data reduction methods that depend directly on crack length measurement are not included in the plot.

A very good agreement between $J$-integral-based results is observed for all test typologies (differences between them below 10\%) and materials (differences below 6\%).

On the other hand, the CC-based data reduction methods are also providing similar results of fracture toughness regardless of the test used (CBTE in ELS, CCM in ENF and CCM in 4ENF), and despite not providing the same accuracy as the $J$-integral-based methods. However, larger differences, compared with the $J$-integral case are observed between the M1 and M2 batches when using CC-based methods (differences up to $16 \%$ in the ELS test). 


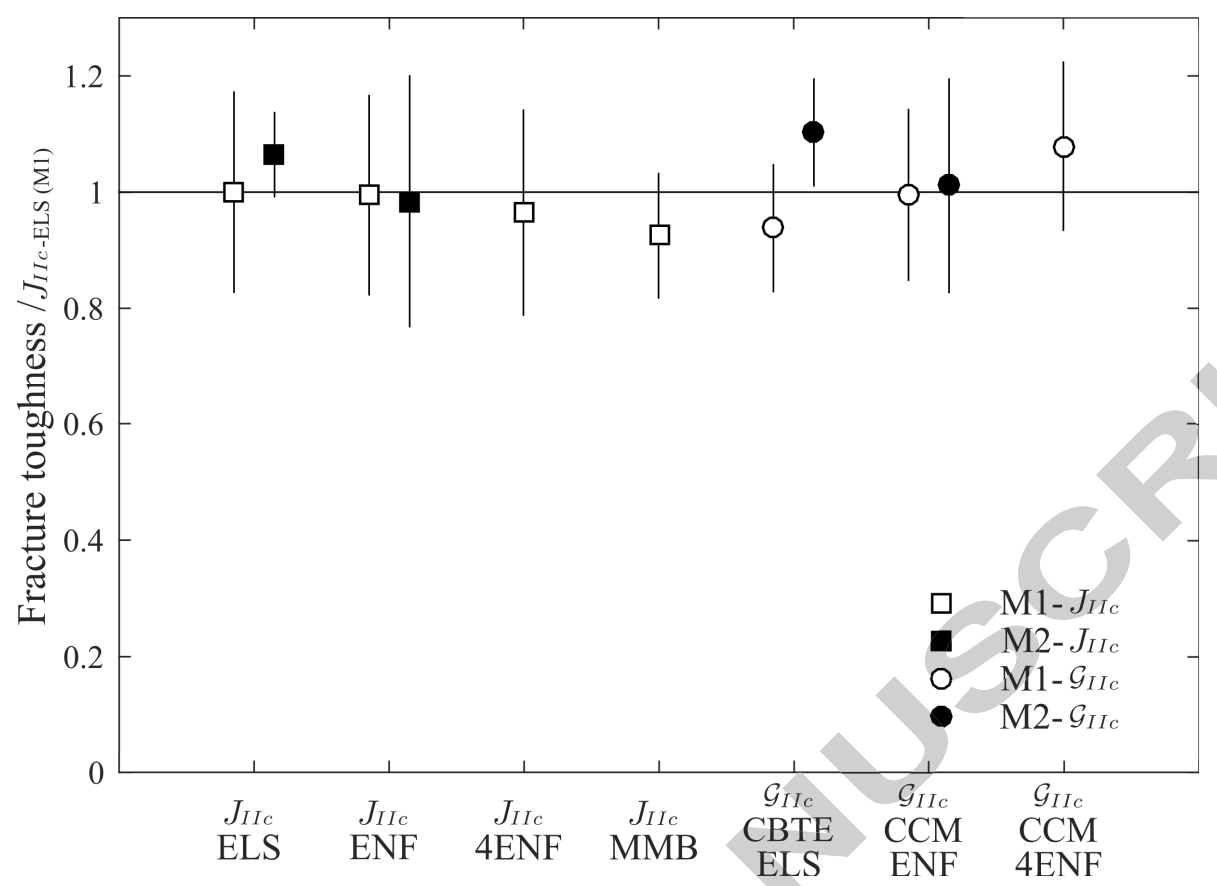

Figure 8: Summary of results. Batch average and standard deviation of each batch normalized with respect to the $J_{I I c}$ average value from all specimens tested.

\section{Conclusions}

With the aim of obtaining a reliable mode II fracture toughness test procedure for structural adhesives, four delamination-based mode II test methods (ELS, ENF, 4ENF and MMB) have been compared through an experimental test campaign with bonded joints between CFRP. Additionally, two specimen typologies (M1 and M2) were tested, with the same adhesive but each with a different adherend. For each test, different data reduction methods were used to obtain the fracture toughness, LEFM and $J$-integral. For this purpose, a data reduction method based on the $J$-integral was developed for the $4 \mathrm{ENF}$ test.

From the analysis of the results, in determining the fracture toughness there were some discrepancies between the tests and the data reduction methods.

The methods based on the visual crack length monitoring show differences in the determination of the fracture toughness because they mainly depend on the measurement of the crack length, and a well defined crack tip does not exist when testing adhesives under mode II loadings. Therefore they 
are not reliable for measuring fracture toughness. On the contrary, methods that are not based on a direct measurement of the crack length, such as CC-based (CBTE in ELS, and CCM in ENF and $4 \mathrm{ENF}$ ) and the $J$-integral, result in small differences between the different test typologies and materials. Even though the CBTE and CCM methods are based on LEFM, they rely on calculating an equivalent crack length that somehow takes into account the FPZ length. This is why their results show better agreement with the $J$-integral approach, based entirely on a non-linear fracture mechanics framework.

In all the tests carried out, the $J$-integral was independent of the test typology and material, but the CC-based methods were also in acceptable agreement with those obtained with the $J$-integral.

During the data analysis, some limitations in the test methods were detected that are summarized next.

The ENF test is very simple, only requiring a common three point bending test fixture. However, the propagation region must be large enough to allow the fracture process zone to fully develop. Even though the span length was increased from $100 \mathrm{~mm}$ to $120 \mathrm{~mm}$ in the specimens tested, the propagation occurred just before the load application point thus resulting in a small range with which to calculate the propagation fracture toughness. This caused larger standard deviations than in the rest of the tests.

Taking into account the same total span length in all the tests $(120 \mathrm{~mm})$, the M2 specimens were broken when tested with the MMB and 4ENF, showing that these tests are more prone to causing premature failure to the specimen before any propagation occurs. Apart from that, they also involve complex test fixtures. In addition, the $4 \mathrm{ENF}$ showed to be highly affected by the friction at the adhesive layer.

Despite involving large deflections and needing to use a more complex test fixture, the ELS test is the best candidate for testing adhesives due to its intrinsic configuration that provides stable and large propagation regions. 


\section{Acknowledgements}

The authors would like to acknowledge the support of the Spanish Government through the Ministerio de Economía y Competitividad under the contracts TRA2015-71491-R and MAT2015-69491-C3-1-R.

\section{Appendix A.}

The $J$-integral closed form for the $4 \mathrm{ENF}$ test has been derived following an analogous procedure to that of the MMB test [23].

The tractions vector in equation (2) is defined as $T_{i}=\sigma_{i j} n_{j}$, where $\sigma_{i j}$ is the stress tensor and $n_{j}$ is a unit vector normal to the integration path. The path enclosing the crack tip $(\Gamma)$ and bounding a region $R$ selected in 4ENF is shown in Figure A.1a. $\Gamma$ runs along the external contour of the specimen and results in the summation of $\Gamma_{a}, \Gamma_{b}, \Gamma_{c}, \Gamma_{d}, \Gamma_{e}, \Gamma_{f}$ and $\Gamma_{g}$. As the selected region $R$ is enclosing the FPZ, the integration path along the specimen external contour, $J_{\Gamma}$, is equal to $J_{T I P}$.

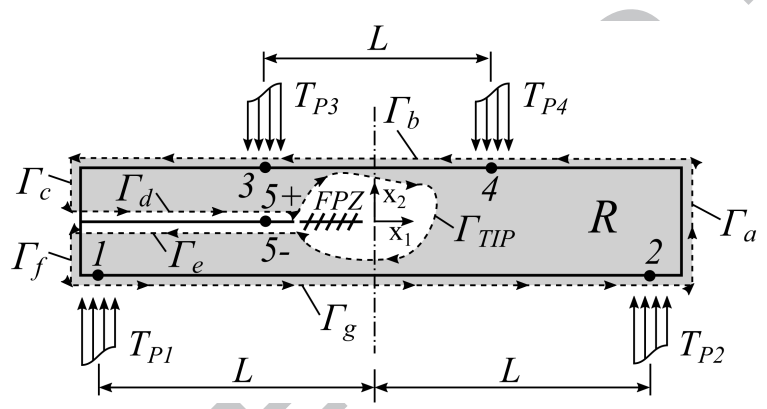

(a) All paths

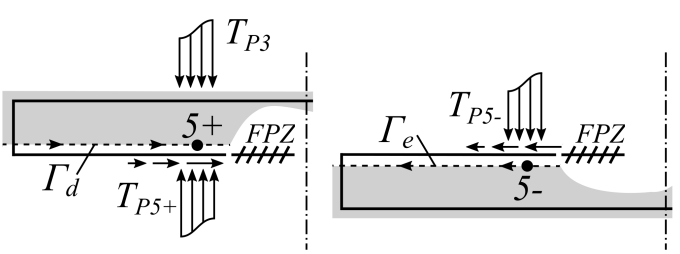

(b) Paths $\Gamma_{d}$ and $\Gamma_{e}$

Figure A.1: External applied loads and integration paths $\Gamma$ in $4 \mathrm{ENF}$ specimen for $J$-integral derivation.

According to Figure A.1a, $\Gamma_{a}, \Gamma_{c}$ and $\Gamma_{f}$ paths are stress-free, therefore $J_{\Gamma_{a}}=J_{\Gamma_{c}}=J_{\Gamma_{f}}=0$. If the vertical tractions in Figure A.1a are considered as concentrated forces applied in an infinitesimal region $\mathrm{d} x_{1}$ at points $\mathrm{P} 1$ to $\mathrm{P} 5$, then $\int \sigma_{22}^{i} \mathrm{~d} x_{1}=P_{i} / W$. Due to the 4 ENF configuration (c.f. 4 ), in points $\mathrm{P} 1$ to $\mathrm{P} 5 P_{i}=P / 2$.

In path $\Gamma_{b}, \mathrm{~d} x_{2}=0$, and the first therm in equation (2) disappear and the normal vector to path $\Gamma_{b}$ is $n=\left[\begin{array}{ll}1 & 0\end{array}\right]$. As $\sigma_{12}$ is zero at points $\mathrm{P} 3$ and $\mathrm{P} 4$, and $\sigma_{22}^{\mathrm{P} 3}$ and $\sigma_{22}^{\mathrm{P} 4}$ take the value of the half external 
applied load, $P / 2$, the traction vectors at points $\mathrm{P} 3$ and $\mathrm{P} 4$ results in $T_{k}^{\mathrm{P} 3}=T_{k}^{\mathrm{P} 4}=-\left[0 \frac{P}{2 W}\right]$.

Following an analogous procedure for path $\Gamma_{g}$, the corresponding traction vectors for points $\mathrm{P} 1$ and $\mathrm{P} 2$ are obtained; $T_{k}^{\mathrm{P} 1}=T_{k}^{\mathrm{P} 2}=\left[0 \frac{P}{2 W}\right]$.

In path $\Gamma_{d}$, the stresses are given by the contact between crack surfaces. Only the friction between the cracked surfaces has been taken into account in the calculations. As contact pressure is much higher below the load application roller, the contact load has been assumed to be a punctual load below the roller contact point (Figure A.1).

The normal vector to path $\Gamma_{d}$ is $n=\left[\begin{array}{ll}-1 & 0\end{array}\right]$ and the corresponding traction yector at point $\mathrm{P} 5+$ results in $T_{k}^{\mathrm{P} 5+}=\frac{P}{2 W}\left[{ }^{\mu 1} 1\right]$. The analogous procedure applied to path $\Gamma_{e}$ results in the traction vector at point $\mathrm{P} 5-T_{k}^{\mathrm{P} 5-}=\frac{-P}{2 W}[\mu 1]$

The derivative of the displacements at points $\mathrm{P} i$ is defined as $\frac{\partial u_{k}}{\partial x_{1}}=\left[\frac{\partial u_{1}^{\mathrm{P} i}}{\partial x_{1}} \frac{\partial u_{2}^{\mathrm{P} i}}{\partial x_{1}}\right]=\left[\varepsilon_{11}^{\mathrm{P} i} \tan \theta_{\mathrm{P} i}\right]$, where $\theta_{\mathrm{P} i}$ is the rotation angle at point $\mathrm{P}_{i}$, positive in counterclockwise direction, and $\varepsilon_{11}^{\mathrm{P} i}$ are the longitudinal strains.

The derivation of $J$ is analogous for all points (P1 to $\mathrm{P} 5$ ) only changing the $T_{k}$ as described before, and $\mathrm{d} s$ depending on the path direction. In doing so, the following expression of the $J$-integral in 4ENF specimen is obtained:

$$
J_{I I}=\frac{P}{2 W}\left(-\tan \theta_{1}-\tan \theta_{2}+\tan \theta_{3}+\tan \theta_{4}-\mu \varepsilon_{11}^{\mathrm{P} 5+} E+\mu \varepsilon_{11}^{\mathrm{P} 5-} E\right)
$$

where $\mu$ is the friction coefficient between crack surfaces, $E$ is the adherend longitudinal young modulus and $\varepsilon_{11}$ are the corresponding longitudinal strains at the contact points in cracked surfaces. By applying Beam Theory, $\varepsilon_{11}$ at points P5+ and P5- are obtained as a function of the span length $(L)$, the specimen dimensions $(W$ and $H)$ and the longitudinal young modulus of the adherend $(E)$ reading

$$
\varepsilon_{11}^{\mathrm{P} 5+}=-\varepsilon_{11}^{\mathrm{P} 5-}=\frac{3 P L}{4 W H^{2} E}
$$


As the rotations at the load application points must be known to calculate the $J$-integral (equation A.1), these can be used to take into account large rotations. If only the vertical component of the forces $\left(P \cos \left(\theta_{n}\right)\right)$ is used in the $J$-integral calculation, and replacing equation A.2 into equation A.1 it results in:

$$
J_{I I}=\frac{P}{2 W}\left(-\sin \theta_{1}-\sin \theta_{2}+\sin \theta_{3}+\sin \theta_{4}-\frac{3 P L \mu \cos \theta_{3}}{2 W H^{2} E}\right)
$$

where $P$ is the applied load, $W$ is the specimen width, $H$ is the half thickness of the specimen, $L$ is the half span length, $\mu$ is the friction coefficient and $\theta_{1}, \theta_{2}, \theta_{3}$ and $\theta_{4}$ are the rotations of the specimen at the roller application edges (c.f. Figure 4).

\section{References}

[1] ASTM D7905M-14 . Standard Test Method for Determination of the Mode II Interlaminar Fracture Toughness of Unidirectional Fiber-Reinforced Polymer. American Society for Testing and Materials 2014;

[2] ISO 15114:2014 . Fibre-reinforced plastic composites - Determination of the mode II fracture resistance for unidirectionally reinforced materials using the calibrated end-loaded split (C-ELS) test and an effective crack length approach. International Standard Organization, Geneva, Switzerland 2014;(1):1-26.

[3] ASTM D6671/D6671M . Standard Test Method for Mixed Mode I-Mode II Interlaminar Fracture Toughness of Unidirectional Fiber Reinforced Polymer Matrix Composites. American Society for Testing and Materials 2013;

[4] Schuecker C, Davidson B. Evaluation of the accuracy of the four-point bend end-notched flexure test for mode II delamination toughness determination. Composites Science and Technology 2000;60:2137-46. 
[5] Davidson B, Sun X, Vinciquerra A. Influences of Friction, Geometric Nonlinearities, and Fixture Compliance on Experimentally Observed Toughnesses from Three and Four-point Bend End-notched Flexure Tests. Journal of Composite Materials 2007;41(10):1177-96. URL: http://jcm.sagepub.com/cgi/doi/10.1177/0021998306067304.

[6] Carité D, Davies P, Peleau M, Partridge IK. The influence of hydrostatic pressure on the interlaminar fracture toughness of carbon/epoxy composites TITRE. Composites Part B: Engineering 2006;37(4-5):292-300. doi:10.1016/j.compositesb.2005.12.002.

[7] Hashemi S, Kinloch A, Williams J. The analysis of interlaminar fracture in uniaxial fiber-polymer composites. Proceedings of the Royal Society A 1990;427:173-99. doi:10.1098/rspa.1990.0007.

[8] Martin R, Davidson B. Mode II fracture toughness evaluation using four point bend, end notched flexure test. Plastics, Rubber and Composites 1999;28(8):401-6. doi:ISSN 1465-8011.

[9] Davidson B, Sun X. Effects of friction, geometry, and fixture compliance on the perceived toughness from three- and four-point bend end-notched flexure tests. Journal of Reinforced Plastics and Composites 2005;24(15):1611-28.

[10] Blackman BRK, Kinloch AJ, Rodriguez-Sanchez FS, Teo WS. The fracture behaviour of adhesively-bonded composite joints: Effects of rate of test and mode of loading. International Journal of Solids and Structures 2012;49(13):1434-52. URL: http://dx.doi.org/10.1016/j.ijsolstr.2012.02.022. doi:10.1016/j.ijsolstr.2012.02.022.

[11] Davies P, Blackman BRK, Brunner A. Standard test methods for delamination resistance of composite materials: current status. Applied Composite Materials 1998;5(Iso 4585):345-64. doi:10.1023/a:1008869811626.

[12] Davies P, Kausch H, Williams J, Kinloch AJ, Charalambides M, Pavan A, et al. Round-robin interlaminar fracture testing of carbon-fibre-reinforced epoxy and PEEK composites. 
Composites Science and Technology 1992;43(2):129-36. URL:

https://www. sciencedirect.com/science/article/pii/026635389290003L.

doi:https://doi.org/10.1016/0266-3538(92)90003-L.

[13] Davies P, Sims G, Blackman BRK, Brunner A, Kageyama K, Hojo M, et al. Comparison of test configurarions for the determination of GIIC: results from an international round robin. Plastics, Rubber and Composites 1999;28(September):432-7.

[14] Davies P. Summary of results from the second VAMAS mode II round robin test exercise using the 4ENF specimen. IFREMER Report TMSI/RED/MS 9982 1999;.

[15] Davies P. Review of standard procedures for delamination resistance testing. In: Delamination Behaviour of Composites. 2008, p. 65-86.

[16] Carlsson L, Gillespie J. Mode-II Interlaminar Fracture of Composites. In: Friedrich K, editor. Application of Fracture Mechanics to Composite Materials; chap. 4. 1989, p. 113-57.

[17] Vassilopoulos AP. Fatigue and Fracture of Adhesively-bonded Composite Joints Behaviour, Simulation and Modelling. 2015. ISBN 9780857092700. doi:10.1016/C2013-0-16372-6.

[18] Blackman BRK, Kinloch A, Paraschi M. The determination of the mode II adhesive fracture resistance, GIIC, of structural adhesive joints: an effective crack length approach. Engineering Fracture Mechanics 2005;72(6):877-97. doi:10.1016/j.engfracmech.2004.08.007.

[19] Högberg J, Sørensen B, Stigh U. Constitutive behaviour of mixed mode loaded adhesive layer. International Journal of Solids and Structures 2007;44(25-26):8335-54. doi:10.1016/j.ijsolstr.2007.06.014.

[20] Rice J. A Path Independent Integral and the Approximate Analysis of Strain Concentration by Notches and Cracks. Journal of Applied Mechanics 1968;35:379-86. doi:10.1115/1.3601206.

[21] Stigh U, Alfredsson KS, Biel A. Measurement of cohesive laws and related problems. 
IMECE2009: Proceedings of the ASME International Mechanical Engineering Congress and Exposition 2009;(11):293-8.

[22] Pérez-Galmés M, Renart J, Sarrado C, Rodríguez-Bellido A, Costa J. A data reduction method based on the J-integral to obtain the interlaminar fracture toughness in a mode II end-loaded split (ELS) test. Composites Part A: Applied Science and Manufacturing 2016;90:670-7. doi:10.1016/j.compositesa.2016.08.020.

[23] Sarrado C, Turon A, Renart J, Costa J. An experimental data reduction method for the Mixed Mode Bending test based on the J-integral approach. Composites Science and Technology 2015;117(117):85-91. doi:10.1016/j.compscitech.2015.05.021.

[24] ISO 25217:2014 . Adhesives - Determination of the mode 1 adhesive fracture energy of structural adhesive joints using double cantilever beam and tapered double cantilever beam specimens. International Organization for Standardization, Geneva, Switzerland 2009;.

[25] AITM 1.0006:1994 . Carbon Fibre Reinforced Plastics Determination of interlaminar fracture toughness energy (Mode II GIIC-TEST). Airbus Industries Test Method 1994;(2):1-8.

[26] Russell A, Street K. Moisture and Temperature Effects on the Mode I and Mode II Interlaminar Fracture of Graphite/Epoxy Composites. Key Engineering Materials 1989;37:199-208. doi:10.1520/STP36314S.

[27] Carlsson LA, Gillespie JW, Trethewey BR. Mode II Interlaminar Fracture of Graphite/Epoxy and Graphite/PEEK. Journal of Reinforced Plastics and Composites 1986;5(3):170-87. doi:10.1177/073168448600500302.

[28] de Moura M, Campilho RDSG, Gonçalves JPM. Pure mode II fracture characterization of composite bonded joints. International Journal of Solids and Structures 2009;46(6):1589-95.

URL: http://dx.doi.org/10.1016/j.ijsolstr.2008.12.001. doi:10.1016/j.ijsolstr.2008.12.001. 
[29] Bhashyam S, Davidson B. Evaluation of data reduction methods for the mixed mode bending test. Aiaa J 1997;35(3):546-52. doi:10.2514/3.13538.

[30] Polaha J, Davidson B, Hudson R, Pieracci A. Effects of Mode Ratio, Ply Orientation and Precracking on the Delamination Toughness of a Laminated Composite. Journal of Reinforced Plastics and Composites 1996;15(2):141-73. URL: http://journals.sagepub.com/doi/pdf/10.1177/073168449601500202.

[31] Blackman BRK, Brunner A, Williams J. Mode II fracture testing of composites: a new look at an old problem. Engineering Fracture Mechanics 2006;73(16):2443-55. doi:10.1016/j.engfracmech.2006.05.022. 
Experimental mode II test campaign of adhesive joints.

Comparison among ENF, ELS, 4ENF and MMB test results.

Comparison between LEFM and NLFM (J-integral) data reduction methods. 